\title{
A novel algorithm for dynamic student profile adaptation based on learning styles
}

\author{
Shaimaa M. Nafea \\ School of Business \\ Arab Academy for Science \\ Technology and Maritime \\ Cairo, Egypt \\ Email: P15017421@my365.dmu.ac.uk
}

\author{
François Siewe \\ School of Computer Science \\ and Informatics \\ De Montfort University \\ Leicester, LE1 9BH \\ United Kingdom \\ Email: fsiewe@dmu.ac.uk
}

\author{
Ying $\mathrm{He}$ \\ School of Computer Science \\ and Informatics \\ De Montfort University \\ Leicester, LE1 9BH \\ United Kingdom \\ Email: ying.he@dmu.ac.uk
}

\begin{abstract}
E-learning recommendation systems are used to enhance student performance and knowledge by providing tailormade services based on the students' preferences and learning styles, which are typically stored in student profiles. For such systems to remain effective, the profiles need to be able to adapt and reflect the students' changing behaviour. In this paper, we introduce new algorithms that are designed to track student learning behaviour patterns, capture their learning styles, and maintain dynamic student profiles within a recommendation system (RS). This paper also proposes a new method to extract features that characterise student behaviour to identify students' learning styles with respect to the Felder-Silverman learning style model (FSLSM). In order to test the efficiency of the proposed algorithm, we present a series of experiments that use a dataset of real students to demonstrate how our proposed algorithm can effectively model a dynamic student profile and adapt to different student learning behaviour. The results revealed that the students could effectively increase their learning efficiency and quality for the courses when the learning styles are identified, and proper recommendations are made by using our method.
\end{abstract}

Keywords-recommender system; dynamic student profile; student modelling; adaptation; algorithms; learning style; behaviour patterns; FSLSM model.

\section{INTRODUCTION}

The dramatic growth of information on the World Wide Web (WWW) has inadvertently led to information overload. Hence, finding a specific piece of information has become difficult and time-consuming [1], [2]. Recommender systems (RSs) are popular personalisation tools to help students find relevant information based on the preferences maintained in their respective profiles. A student profile [3] represents a student's background, goals, learning styles, interests, and preferences. One of the main components of a student profile is learning styles. A learning style (LS) consists of various factors that describe how a student interacts with his or her learning environment [4]. Learning styles are particularly important in an e-learning environment since they may help the system personalise the learning process according to learners' personal characteristics. According to several studies, adaptive e-learning environments based on specific learning styles are not only more productive, but also create higher student satisfaction levels, diminish learning times, and increase students' academic achievement [5], [6], [7], [6], [8], [7], [9]. Many studies [10], [5], [11] observe that students with a strong preference for a specific learning style have difficulty learning when this learning style is not supported by the teaching environment, such mismatches lead to poor student performance. The challenge of improving adaptive learning processes largely depends on correctly identifying each student's learning style. Traditionally, the classical method for detecting learning styles is based on asking students for a test or to fill out a questionnaire (collaborative approach). Despite these traditional techniques' reliability, they suffer from many limitations that weaken the precision of identifying learning styles. Firstly, student's boredom to fill out questionnaires, since some of them require extra effort and concentration. Secondly, the questionnaire technique assumes that students are conscious of their learning styles and preferences, which may not always be the case. Two other approaches to identify learning styles automatically are displayed in Fig.1. These automatic approaches include the following:

a) Data-driven approach: This approach is focused on building a model that imitates the Inventory Learning Style questionnaire and uses sample data to develop a model. The common techniques used for the datadriven approach are decision trees, neural networks, fuzzy clustering, and Bayesian networks [12], [13].

b) literature-based approach: This approach uses the students' behaviours to identify their learning style preferences. Then, it applies a simple rule-based method to calculate learning styles from behaviours such as the number of matching hints, time spent on learning objects etc. [14], [15], [16], [17].

\section{A. Motivation and problem statement}

The motivation for this paper is to build dynamic student profile based on Learning Behaviour Patterns, which is called DPSP (Dynamic Personalised Student Profile) for the purpose of learning style identification. Previous researches on student profile adaptation suffer from many limitations that weaken the precision of identifying learning styles, as follows:

- First, it takes long time in getting the behaviour patterns of students who participate in the online learning and sometimes the patterns of the behaviour obtained from the data are not strong enough [18][19]. 


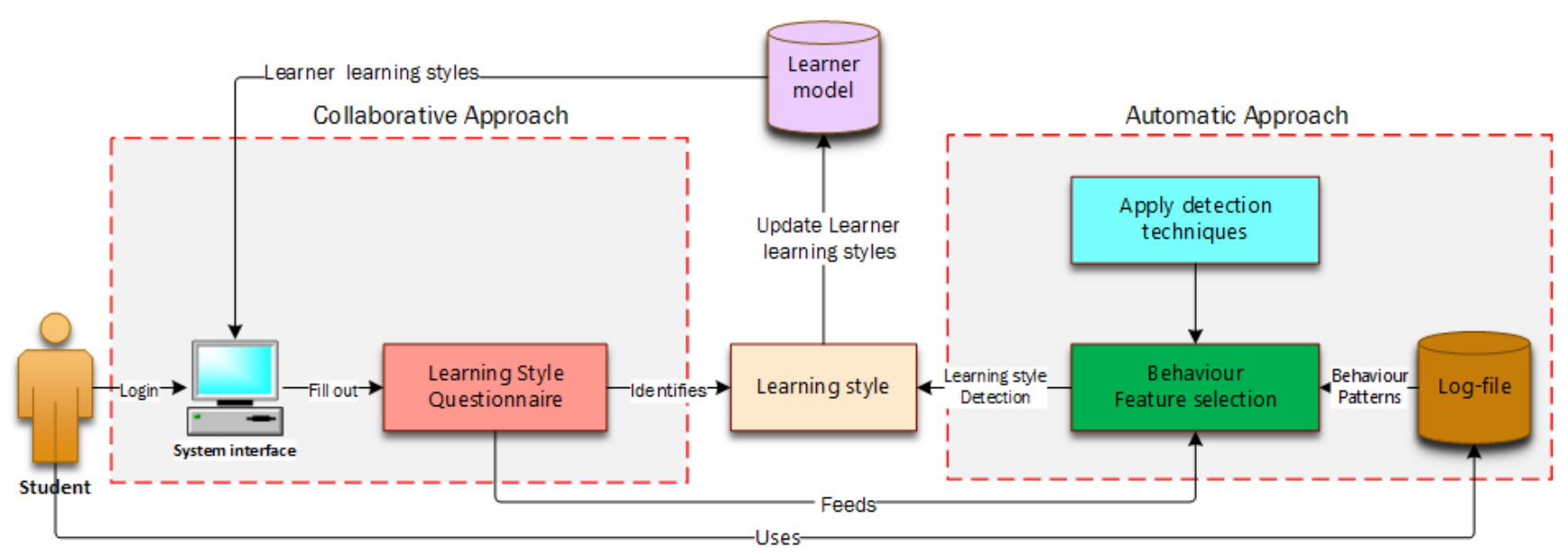

Fig. 1. Identification of learning styles and automatic detection of learning styles

- Second, there is uncertainty in student behaviour identification, as well as difficulty and complexity in developing and implementing rules that can infer learning styles effectively from student's actions.

- Third, current e-learning recommendation systems are not capable of detecting changes in students' learning styles due to the change in their behaviour patterns. For example CS383 [20], eTeacher [21], and LSAS [5], use questionnaires (a static or collaborative approach). Furthermore, student profiles in these systems are created only once at the course's beginning without the possibility for later updates [22].

In order to avoid these drawbacks and improve the accuracy of learning styles identification, this research considers student exceptional behaviours and updates student learning styles frequently since they change over time.

\section{B. Expected contributions}

This paper makes the following contributions:

- Firstly, a novel algorithm for dynamic student profile adaptation based on the FSLSM learning style model is proposed (Section III).

- Secondly, a new approach is proposed to identify learning behaviour patterns based on the time spent on learning objects, the number of messages exchanged, and the format of the learning objects accessed by the student (Sect. IV).

- Thirdly, a method is proposed to transform learning behaviour patterns into the FSLSM learning style preferences (Sect. V); which are then used to update the student profile dynamically (see Sect. VI).

Our algorithm, DPSP, has been implemented in C++ using Visual Studio and Windows Presentation Foundation (WPF) to design the Graphical User Interface (GUI), and evaluated using a real academic case study. The students participated voluntarily in the study from Arab Academy for Science and Technology (AAST) (see Sect. VII).
The rest of this paper is structured as follows. The next section defines the proposed algorithm's main concepts. Sections III and IV describe our proposed algorithm for automatically detecting of learning style through learning behaviour. Sections $\mathrm{V}$ and VI describe the student profile adaptation. Section VII presents a case study. Sections VIII and IX present the experimental results and analysis. Related works are discussed in Section X, and Section XI concludes the paper and discusses future directions.

\section{BASIC CONCEPTS AND BACKGROUND}

In this section, we will introduce concepts that student profile construction are based on the Felder-Silverman Learning Style Model (FSLSM) and student modelling.

\section{A. Description of the Felder-Silverman learning style model}

Several authors proposed different definitions for learning style [23], [24], [25]. One study [26] defines learning style as the complex manner in which, and conditions under which, learners most efficiently and most effectively perceive, process, store, and recall what they are attempting to learn. Several learning style theories exist in literature; for example, Kolb [27], Honey and Mumford [28], Dunn and Dunn [29], MyersBriggs [30], and Felder-Silverman [6]; all have developed learning style models. In our case, we use the Felder and Silverman model [6] for several reasons: First, it is the most widely used in educational systems thanks to its ability to quantify students' learning styles as displayed in Table II. [31] observes that the FSLSM stands out from other theories by combining the main learning Style $(L S)$ models. Second, it provides comprehensive details of its dimensions (processing, input, understanding, and perception), identifies a teaching style for each dimension, and comes with a reliable and validated learning style assessment tool as shown in Table I. Finally, the FSLSM theory describes students' learning styles preferences for each dimension that can be strong, moderate, or balanced, based on a scale from +11 to -11 for each dimension. E.g., in visual/verbal dimension, the value +11 means that a learner has a strong preference for visual learning style, whereas the value -11 states that a learner has a strong preference for verbal learning. Felder and A Soloman [32] 
TABLE I. FELDER-SILVERMAN'S LEARNING STYLE DIMENSIONS

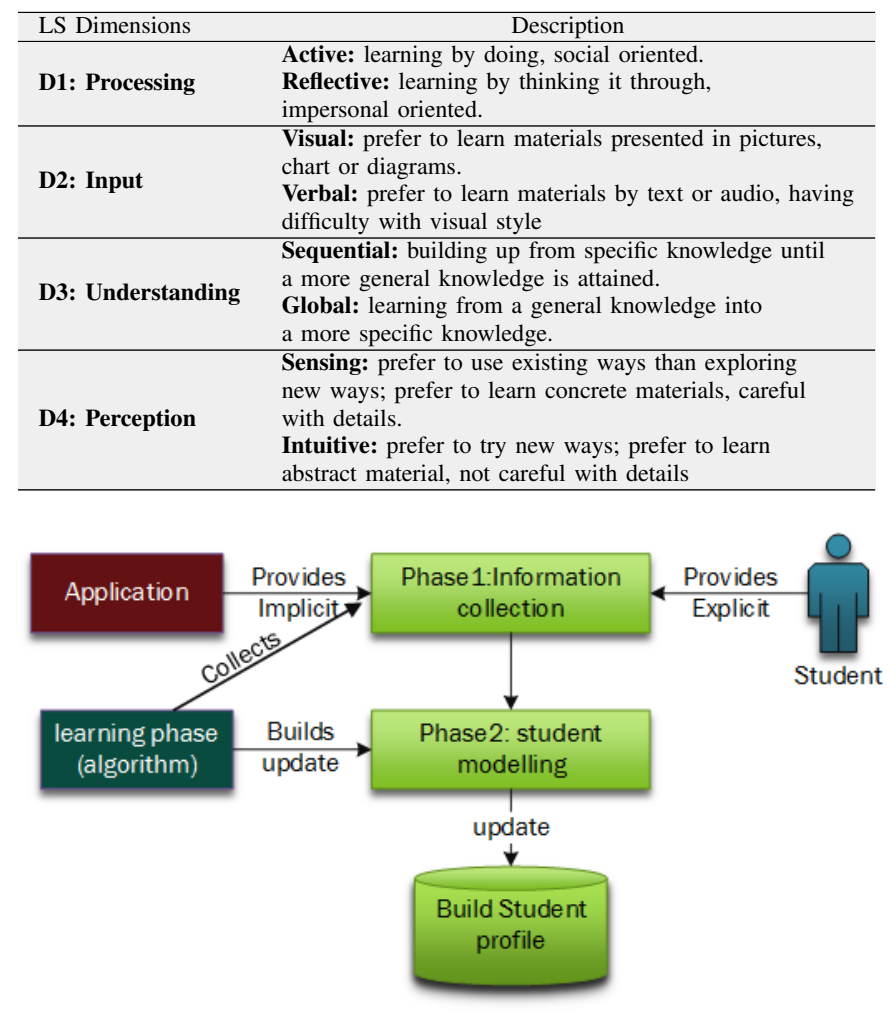

Fig. 2. Student modelling in e-learning systems

developed the Index of Learning Styles (ILS) questionnaire that comprises 44 questions effective in identifying the learning style of each individual student. ILS provides a method of calculating the learning style preferences from the student's answers to the questionnaire [32], [33].

\section{B. Student modelling}

The student model tracks an individual student's information in order to adapt itself to the student's interests and preferences [43]. In this context, [44] states that the student model is considered a critical piece of individualised behaviour in e-learning recommendations, which strongly depend on how the knowledge about the student is modelled internally. The process of building and updating a Student Profile (SP) is called student modelling. Figure 2 highlights the student modelling phases. Student modelling can be classified into static or dynamic modelling as described below:

- Static modelling refers to an approach in which the student model is initialised only once, usually when the student enrols in the system [45].

- Dynamic modelling refers to an approach that updates the student information, and then allows the system to respond to changes in the student model during the course [45].

Table II illustrates examples of systems that use an explicit (using questionnaire) or implicit (using behaviour) modelling approach or both. In the next section, the proposed algorithm for the dynamic student profile component is described.

\section{CAPturing And Modelling Dynamic Student PROFILE}

In this section, a study is executed to develop an effective algorithm for building and frequently updating SP learning styles. To achieve this goal, the proposed algorithm observes a student's behaviour while s/he is taking a course via an elearning system. The agent records the student's actions and then it uses these data to build the SP.

Definition 1. (A student profile learning style) is represented by a vector of real values ranging from 0 to 1 (or from $0 \%$ to $100 \%$ ) as follows:

$$
L S=[a c t, r e f, \text { vis, ver, seq, glo, sen, int }]
$$

Example 1: Table III shows some examples of student's learning style vectors. As stated in Sect. II-A, the SP learning style vector can be calculated using e.g. the learner's responses to the ILS questionnaire [33].

\section{A. Proposed architecture for dynamic student profile}

The proposed model's overall structure is presented in Fig. 3. The algorithm includes the following basic steps:

- Step 1: Information retrieval. The system log-file is analysed to extract information about the student behaviour such as the time spent by the student on each learning object, the type of learning objects accessed (e.g. video, audio, or text), and the number of messages exchanged (see Sect. IV).

- Step 2: Dynamic checking sessions. In order to build the student profile, we need to observe, process and then learn from student behaviour patterns. Therefore, in this step the student behaviour patterns identified in Step 1 are converted into FSLSM learning style preferences. The result is a feature vector of FSLSM learning style preferences extracted from the student learning behaviour patterns (see Sect. V).

- Step 3: Profile adaptation phase. The student is observed over a number of sessions and the corresponding feature vectors are aggregated to approximate the student's current learning style preferences (see Sect. V).

- Step 4: Updating student profile. The current student's learning style obtained in Step 3 and the previous student's learning style are used to calculate a new student learning style which is then stored in the student profile database. The new student learning style will be used to provide students with personalised course learning objects the next time s/he logs in (see Sect. VI).

The following section describes in detail how the algorithm calculates a student learning style.

\section{STUDENT LEARNING BEHAVIOUR PATTERNS}

The algorithm in Fig. 4 calculates a student's learning style dynamically based on learning behaviour patterns. In order to ensure that the proposed algorithm is general enough to apply to any learning system, it was key to base the approaches 
TABLE II. SUMMARY OF STUDENT MODELING APPROACHES IN EXISTING PERSONALISED E-LEANING SYSTEMS CONSIDERING LEARNING STYLES

\begin{tabular}{|c|c|c|c|}
\hline \multirow[b]{2}{*}{ System Name } & \multirow[b]{2}{*}{$\begin{array}{c}\text { learning style } \\
\text { model }\end{array}$} & \multicolumn{2}{|c|}{ Student modelling approach } \\
\hline & & Explicit modelling (Questionnaire) & Implici tmodelling (Behaviour Pattern) \\
\hline MAS-PLANG [34] & FSLSM & $\checkmark$ & $\checkmark$ \\
\hline WELSA [35] & Unified LS Model & & $\checkmark$ \\
\hline TANGOW [36] & FSLSM (understanding and perception) & $\checkmark$ & \\
\hline shaboo [37] & FSLSM & $\checkmark$ & \\
\hline e-Teacher [21] & FSLSM (perception, processing, understanding) & $\checkmark$ & $\checkmark$ \\
\hline CS388 [20] & FSLSM & $\checkmark$ & \\
\hline iWeaver [38] & Dunn \& Dunn Model & $\checkmark$ & \\
\hline LSAS [5] & FSLSM(Sequential/global) & $\checkmark$ & \\
\hline PLORS [39] & FSLSM & $\checkmark$ & \\
\hline DeLeS [40] & FSLSM & & $\checkmark$ \\
\hline Protus [41] & FSLSM & $\checkmark$ & $\checkmark$ \\
\hline OSCAR CITS [42] & FSLSM & & $\checkmark$ \\
\hline
\end{tabular}

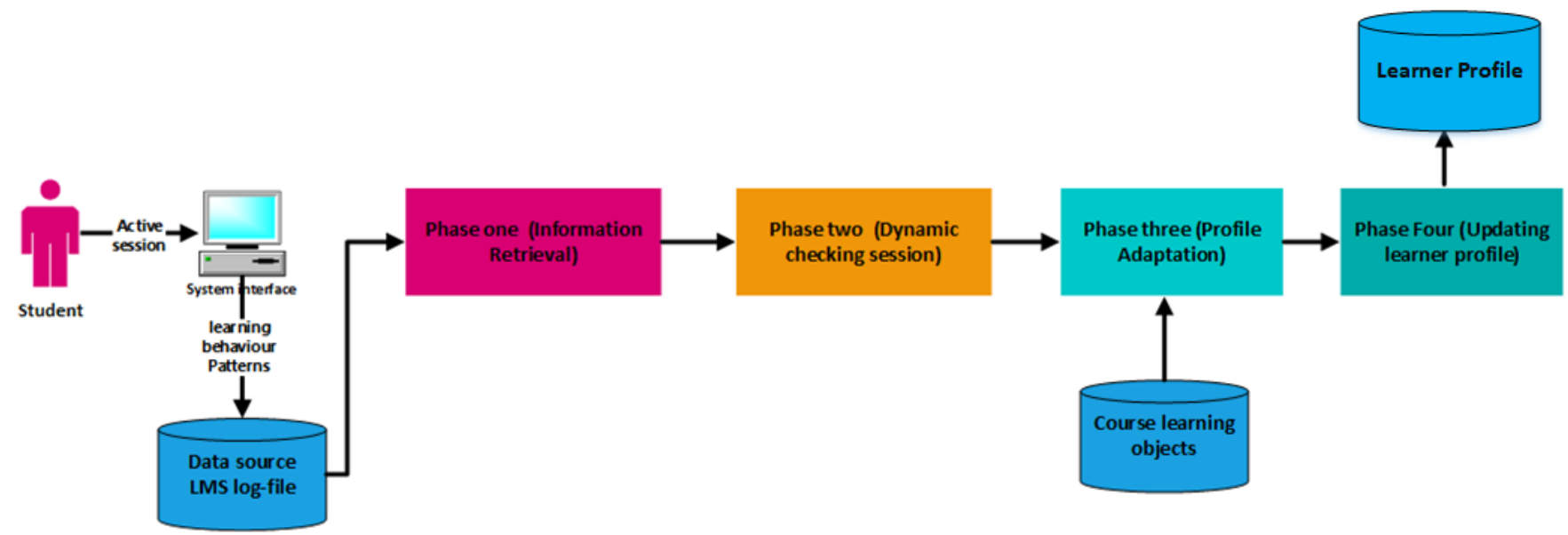

Fig. 3. Architecture for updating student profile dynamically

TABLE III. EXAMPLES OF STUDENT LEARNING STYLE VECTORS

\begin{tabular}{|c|c|c|c|c|c|c|c|c|}
\cline { 2 - 9 } \multicolumn{1}{c|}{} & act & ref & vis & ver & seq & glo & sen & int \\
\hline Fatima & 0.4 & 0.6 & 0.35 & 0.75 & 0.5 & 0.5 & 0.8 & 0.2 \\
\hline Ali & 0.5 & 0.5 & 0.6 & 0.4 & 0.8 & 0.2 & 0.7 & 0.3 \\
\hline
\end{tabular}

on generic behaviour patterns that can be collected in any learning system. Three variables are used to model the learning behaviour patterns of a student. The first variable is the time spent on each learning object; the second is the number messages sent; and the third is the format of the learning objects accessed during a session. If a student watches more than $50 \%$ of a video, then it is more likely that the student is an active learner than a reflective learner. Conversely, if a student spent more than $50 \%$ of time on textual documents (e.g. pdf or doc documents), then the student is more likely to be reflective than active. Therefore, the behaviour pattern for time spent $W_{i}$ is calculated as in Eq. (2), for each learning object $L O_{i}$. Table IV shows the rules for deciding the learning styles corresponding to a given behaviour pattern.

$$
W_{i}= \begin{cases}\frac{t_{i}}{T_{i}} & \text { (For Video, Audio, Simulation) } \\ \frac{t_{i}}{T} & \text { (For PDF, PPT, Doc, Summary, Outline) }\end{cases}
$$

Where $t_{i}=$ time spent on $L O_{i}, T_{i}=$ total duration of $L O_{i}$, and $T=$ total session duration.

Example 2: Table V shows the learning styles of 3 students calculated based on the time they have spent on learning objects.
The number of messages posted in the course discussion forum can indicates a student's tendency for social orientation, i.e. whether the student is active or reflective. We used the following Eq. (3).

$$
D=\frac{\text { Number of messages sent by the student }}{\text { Average number of messages sent during the sessions }}
$$

The value of $D$ is undefined if no messages have been exchanged during the session. A greater value of $D$ indicates a stronger positive level of active learning, since active students are likely to post messages more often than passive ones. If the value of $D$ is greater than or equal 1 , the student is considered to be active; otherwise the student is reflective.

Example 3: Table VI illustrates the case where 3 students Fatima, Ali, and Clara have exchanged 100 messages throughout the session, i.e. $100 / 3=33.3$ messages in average have been sent per student. Fatima is reflective because she has sent less than the average number of messages, while Ali and Clara are active for sending more than the average number of messages during the session.

The formats of the learning objects accessed by a student define the learning style of the student as in Table VII. The symbol "-" in yellow cells means that learning objects of that format are irrelevant to the corresponding leaning style attribute. The value 1 indicates the learning style attribute associated to that format in the learning style dimension. The value 0.5 indicates that both learning style attributes of the dimension are associated to that format. 
TABLE IV. BeHAVIOUR PATtERn BASED ON LEARNING OBJECT TYPE AND FELDER AND SiLVERMAN

\begin{tabular}{|c|c|c|c|c|}
\hline Learning Object & Behaviour Pattern & Pattern Description & \multicolumn{2}{|c|}{ Learning Style criteria } \\
\hline video & Time_spent & $\begin{array}{l}\text { Time spent on video content } \\
\text { (based on predefined video actual time) }\end{array}$ & $\begin{array}{l}>=50 \% \text { Active } \\
>=50 \% \text { visual }\end{array}$ & $\begin{array}{l}<50 \% \text { Reflective } \\
<50 \% \text { verbal }\end{array}$ \\
\hline \multirow{2}{*}{ Audio } & \multirow{2}{*}{ Time_spent } & \multirow{2}{*}{$\begin{array}{l}\text { Total time spent on Audio content } \\
\text { (based on predefined Audio actual time) }\end{array}$} & $>=50 \%$ Reflective & $<50 \%$ Active \\
\hline & & & $>=50 \%$ verbal & $<50 \%$ visual \\
\hline Simulation & Time_spent & $\begin{array}{l}\text { Total time spent on simulation content } \\
\text { (based on predefined simulation actual time) }\end{array}$ & $>=50 \%$ Active & $<50 \%$ Reflective \\
\hline PPT & Time_spent & $\begin{array}{l}\text { Total time spent on PPT content } \\
\text { (based on total session duration) }\end{array}$ & $\begin{array}{l}>=50 \% \text { Global } \\
>=50 \% \text { Active } \\
>=50 \% \text { Intuitive }\end{array}$ & $\begin{array}{l}<50 \% \text { Sequential } \\
<50 \% \text { Reflective } \\
<50 \% \text { Sensing }\end{array}$ \\
\hline PDF and Doc & Time_spent & $\begin{array}{l}\text { Total time spent on PDF content } \\
\text { (based on total session duration) }\end{array}$ & $\begin{array}{l}>=50 \% \text { Sequential } \\
>=50 \% \text { Reflective } \\
>=50 \% \text { Intuitive } \\
>=50 \% \text { verbal }\end{array}$ & $\begin{array}{l}<50 \% \text { Global } \\
<50 \% \text { Active } \\
<50 \% \text { Sensing } \\
<50 \% \text { visual }\end{array}$ \\
\hline Summary & Time_spent & $\begin{array}{l}\text { Total time spent on Summary content } \\
\text { (based on total session duration) }\end{array}$ & $>=50 \%$ Global & $<50 \%$ Sequential \\
\hline Outline & Time_spent & $\begin{array}{l}\text { Total time spent on Outline content } \\
\text { (based on total session duration) }\end{array}$ & $>=50 \%$ Global & $<50 \%$ Sequential \\
\hline
\end{tabular}

TABLE V. AN EXAMPLE OF TIME SPENT

\begin{tabular}{llll}
\hline Student (time spent) & LO (length) & W & Learning style \\
\hline Fatima $(30 \mathrm{~min})$ & video $(40 \mathrm{~min})$ & $30 / 40=75 \%$ & LS = Visual \\
\hline Ali $(30 \mathrm{~min})$ & PDF $(35 \mathrm{~min})$ & $30 / 35=85 \%$ & LS = Verbal \\
\hline Clara $(45 \mathrm{~min})$ & Audio $(60 \mathrm{~min})$ & $45 / 60=75 \%$ & LS = Verbal \\
\hline
\end{tabular}

TABLE VI. AN EXAMPLE OF FORUM DISCUSSION

\begin{tabular}{lll}
\hline Student (no. of messages) & D & Learning style \\
\hline Fatima (25 messages) & $25 / 33.3=0.75$ & LS =Reflective \\
\hline Ali (40 messages) & $40 / 33.3=1.20$ & LS =Active \\
\hline Clara (35 Massages) & $35 / 33.3=1.05$ & LS =Active \\
\hline
\end{tabular}

Both learning style calculation and student profile adaptation are described in the following sections.

\section{FROM BEHAVIOUR PATTERNS TO LEARNING STYLES}

The learning style adaptation algorithm in Fig 4 observes the student behaviours over $K$ sessions and calculates in the vector $K S S P$ the number of hits for each of the 8 learning style attributes according to the student learning behaviour patterns as explained in Sect. IV. For example, $K S S P[1]$ is the number of hits for the learning style "active", $K S S P[2]$ is the number of hits for the learning style "reflective", and $K S S P[8]$ is the number of hits for the learning style "intuitive", using the same indexing as in Eq. (1).

At the end of the $K$ sessions, the number of hits are normalised in each dimension as in Eq. (4) to obtain the current learning style vector $K S S P \_N$.

$$
\begin{aligned}
& \text { for } i=1: 2: 8 \text { do } \\
& \text { if }(K S S P[i]+K S S P[i+1] \neq 0) \\
& \quad K S S P \_N[i]=\frac{K S S P[i]}{K S S P[i]+K S S P[i+1]} \\
& \quad K S S P_{-} N[i+1]=\frac{K S S P[i+1]}{K S S P[i]+K S S P[i+1]} \\
& \text { else } \\
& \quad K S S P_{-} N[i]=0 \\
& \quad K S S P_{-} N[i+1]=0 \\
& \text { endif } \\
& \text { enddo }
\end{aligned}
$$

Tables IX and X illustrate how the vectors KSSP and KSSP_N are calculated.

\section{Updating StUdENT PROFILE}

The final step is to update dynamically the student profile $S P$ using the learning style $K S S P_{-} N$ calculated during the $K$ sessions. This is done by calculating the new value of $S P$ as in Eq. (5).

$$
\begin{aligned}
& \text { for } i=1: 8 \text { do } \\
& \text { if }\left(K S S P_{-} N[i] \neq 0\right) \\
& \quad S P[i]=\frac{S P[i]+K S S P_{-} N[i]}{2} \\
& \text { endif } \\
& \text { enddo }
\end{aligned}
$$

That is for each learning style attribute $i, i=1,2, \cdots, 8$, if $K S S P \_N[i] \neq 0$, then calculates the new learning style value by taking the average between previous and current learning style values; otherwise keep the previous learning style value. The new student profile $S P$ will be used to recommend personalised learning objects to the student the next time s/he logs in, using the learning style based recommender system proposed in [46].

An important question remains, however: "is the proposed profile adaptation algorithm effective in predicting student learning styles?" The following section illustrates how the algorithm works using a real academic case study.

\section{MODELING A REAL ACADEMIC CASE STUDY}

After developing the proposed algorithm, our efforts were focused on modelling a real academic case study to demonstrate how the proposed algorithm works. Participants to the study from AAST were asked to fill out FSLSM questionnaire in order to initialise their profiles as shown in Table III.

\section{A. Profile adaptation scenario}

The student profile (SP) learning style adaptation algorithm works as follows:

Step 1-Recommend course learning objects according to their similarity to SP learning styles as explained in [46] and in Table VIII.

Step 2 - Collect student behaviour during $K$ sessions (in this 
TABLE VII. MAPPING OF LEARNING OBJECTS FORMAT AND ACTIVITIES AS FSLSM

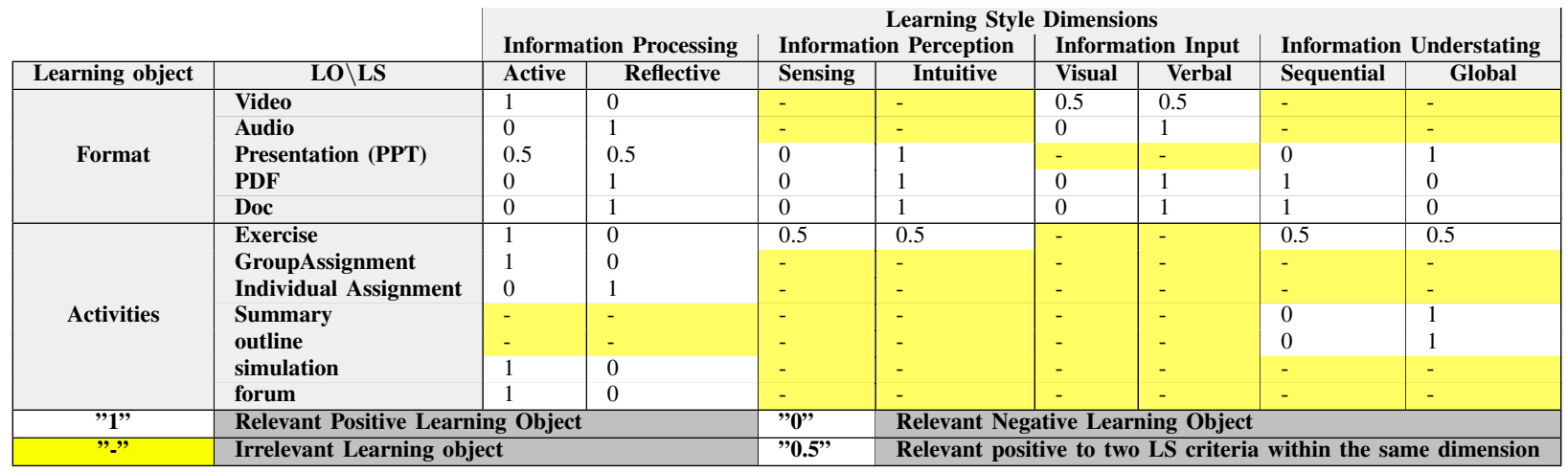

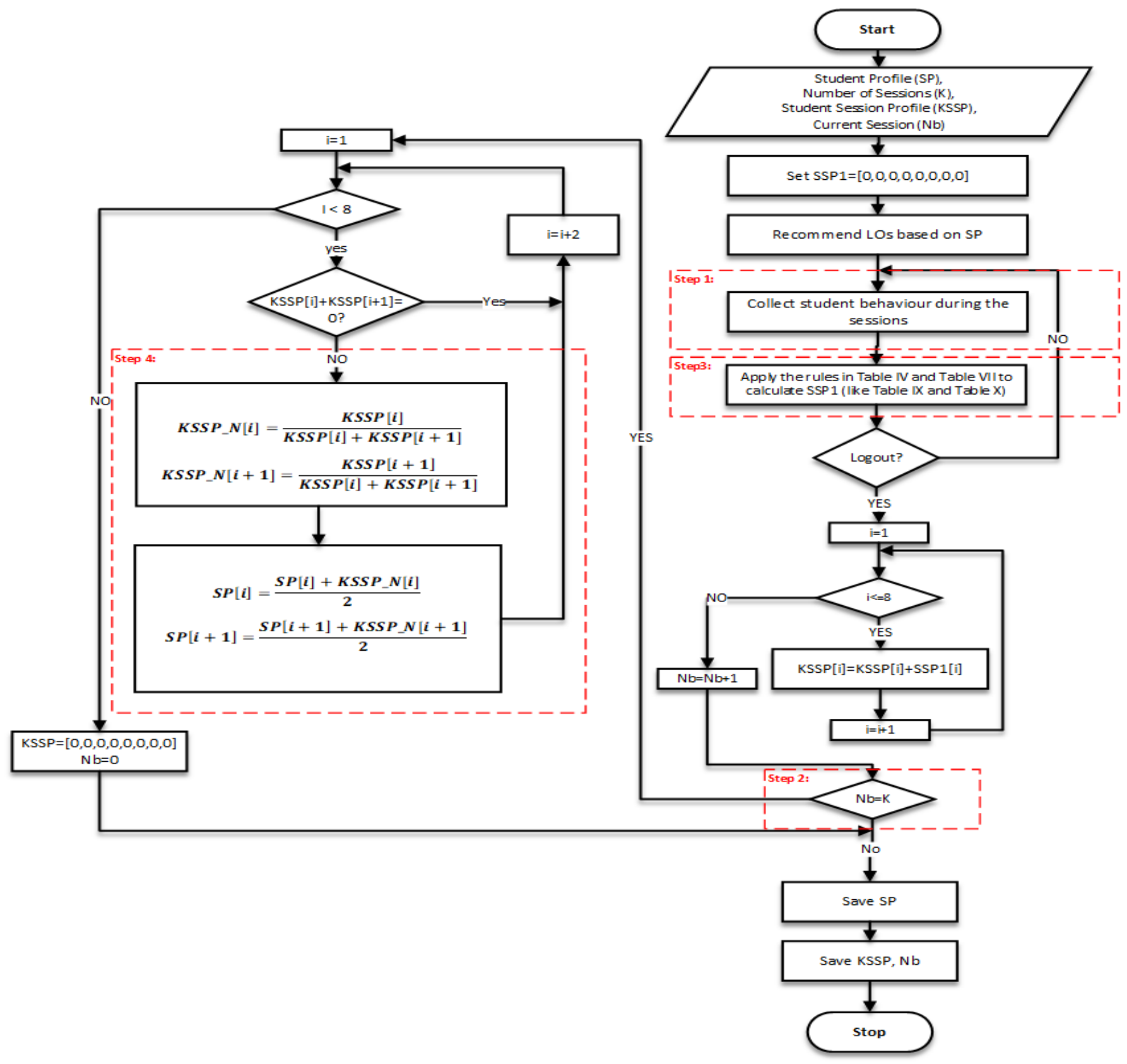

Fig. 4. Updating student profiles dynamically flowchart 


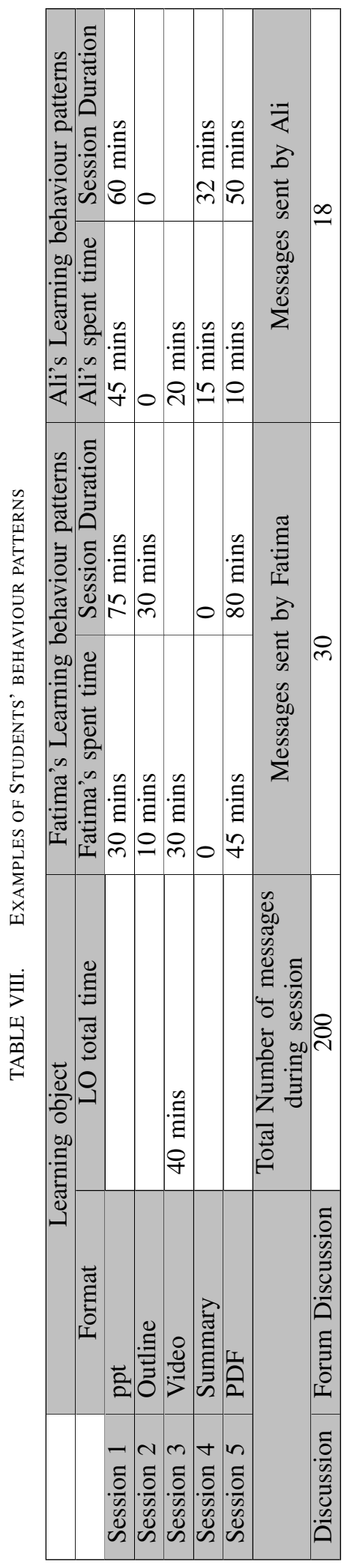

case $K=5$ ). Table VIII depicts a sample from Fatima and Ali learning behaviour patterns.

Step 3 - Apply adaptation rules as illustrated in Table IV and Table VII. First, the algorithm calculates the total time spent by Fatima and Ali on Learning objects (see Sect.IV). Second, it calculates the number of messages sent by Fatima and Ali during the sessions as illustrates in Table VIII. The average number of messages is $200 / 8=25$, where 8 is the total number of participants during the forum discussion (See Sect. IV). Then, $K S S P$ and $K S S P \_N$ are calculated as shown in Table IX and Table X, for Fatima and Ali respectively.

Step 4 - Update Fatima's and Ali's profiles with the new learning styles as shown in Table XI and Table XII.

In order to evaluate the effectiveness of the proposed algorithm, the updated SPs are used to predict the students' ratings of the learning objects in the following section.

\section{STUDENT RATINGS PREDICTION BASED ON STUDENT LEARNING STYLE}

This section presents an experimental student rating prediction algorithm. We aim to demonstrate that our approach on dynamic student profile adaptation can effectively capture student learning styles from their behaviour pattern and can be used as part of e-learning recommendation system to provide more effective and accurate course learning objects to students. Let $L S$ be the learning style vector of the active student. The recommender algorithm is described in the following four steps:

Step 1 - Calculate $C$, the nearest learning object cluster to the active student learning style (LS) by using the cosine similarity metric: This result is achieved by calculating the similarity degree between LS and the centroid of each cluster and then choosing the cluster that produces the highest similarity degree using cosine similarity defined in Eq. (6).

$$
c(x, y)=\frac{x \cdot y}{\|x\| \cdot\|y\|}
$$

Step 2 - Calculate the similarity degree between $L S$ and each learning object in $C$ using the Pearson correlation coefficient similarity metric: For all $O P \in C$, calculate $P(L S, O P)$ using Pearson correlation coefficient in Eq. (7).

$$
P(x, y)=\frac{\sum_{i=1}^{n}\left(x_{i}-\bar{x}\right)\left(y_{i}-\bar{y}\right)}{\sqrt{\sum_{i=1}^{n}\left(x_{i}-\bar{x}\right)^{2}} \sqrt{\sum_{i=1}^{n}\left(y_{i}-\bar{y}\right)^{2}}}
$$

Step 3 - Select the top-n learning objects most similar to $L S$ : The number of selected learning objects can be a chosen constant or determined using a similarity threshold.

Step 4 - Predict the Student's ratings of the top-n learning objects: A 5-level Likert scale is considered where 1 is the lowest score and 5 is the highest score. The student's ratings of the learning objects are predicted using Eq. (8).

$$
\tilde{r}\left(L S, O P_{i}\right)=\operatorname{int}\left(0.5+\operatorname{Sim}_{2}\left(L S, O P_{i}\right) \times 5\right), \quad 1 \leq i \leq n
$$

where $\tilde{r}\left(L S, O P_{i}\right)$ is the predicted rating of the learning object (Profile) $O P_{i}$ for the active student $L S$ and $\operatorname{int}(x)$ denotes the closest integer to the real value $x$; e.g. $\operatorname{int}(2.3)=2$ and $\operatorname{int}(2.5)=3$. We subsequently compare the student 
TABLE IX. KSSP CALCULATION FoR FATIMA'S BEHAVIOUR

\begin{tabular}{|c|c|c|c|c|c|c|c|c|c|}
\hline \multicolumn{2}{|c|}{ Fatima's behaviour } & Active & Reflective & Visual & Verbal & Sequential & Global & Sensing & Intuitive \\
\hline $\mathrm{PPT}=30 / 75=0.4$ & PPT < 50\% : & 0.5 & 0.5 & & & 1 & & 1 & \\
\hline Outline $=10 / 30=0.35$ & Outline $<50 \%$ & & & & 1 & 1 & & & \\
\hline Video $=30 / 40=0.75$ & Video $>=50 \%$ & 1 & & 0.5 & 0.5 & & & & \\
\hline Summary $=0$ & No behaviour & & & & & & & & \\
\hline $\mathrm{PDF}=45 / 80=0.56$ & PDF $>=50 \%$ & & 1 & & 1 & 1 & & & 1 \\
\hline Messages $=30 / 25=1.2$ & $\mathrm{D}>=50 \%$ & 1 & & & & & & & \\
\hline & & & KSSP Cal & ation & & & & & \\
\hline$K S S P$ & & 2.5 & 1.5 & 0.5 & 2.5 & 3 & 0 & 1 & 1 \\
\hline$K S S P_{-}$ & & 0.63 & 0.37 & 0.17 & 0.83 & 1 & 0 & 0.5 & 0.5 \\
\hline
\end{tabular}

TABLE X. KSSP CALCULATION FOR ALI'S BEHAVIOUR

\begin{tabular}{|c|c|c|c|c|c|c|c|c|c|}
\hline \multicolumn{2}{|c|}{ Ali's behaviour } & Active & Reflective & Visual & Verbal & Sequential & Global & Sensing & Intuitive \\
\hline $\mathrm{PPT}=45 / 60=0.4$ & PPT $<50 \%$ & 0.5 & 0.5 & & & 1 & & 1 & \\
\hline Outline $=0$ & No behaviour & & & & & & & & \\
\hline Video $=15 / 40=0.37$ & Video $<50 \%$ & & 1 & 0.5 & 0.5 & & & & \\
\hline Summary $=15 / 32=0.46$ & Summary $<50 \%$ & & & & & 1 & & & \\
\hline $\mathrm{PDF}=10 / 50=0.20$ & PDF $<50 \%$ & 1 & & 1 & & & 1 & 1 & \\
\hline Messages $=18 / 25=0.72$ & $\mathrm{D}<50 \%$ & & 1 & & & & & & \\
\hline & & & KSSP Calc & tion & & & & & \\
\hline$K S S I$ & & 1.5 & 2.5 & 1.5 & 0.5 & 2 & 1 & 2 & 0 \\
\hline$K S S P$ & & 0.37 & 0.63 & 0.75 & 0.25 & 0.67 & 0.33 & 1 & 0 \\
\hline
\end{tabular}

TABLE XI. FATIMA 's UPDATED LEARNING STYLE PROFILE

\begin{tabular}{|l|c|c|c|c|c|c|c|c|}
\cline { 2 - 9 } \multicolumn{1}{c|}{} & act & ref & vis & ver & seq & glo & sen & int \\
\hline Fatima's SP & 0.4 & 0.6 & 0.35 & 0.75 & 0.5 & 0.5 & 0.8 & 0.2 \\
\hline KSSP_N & 0.63 & 0.37 & 0.17 & 0.83 & 1 & 0 & 0.5 & 0.5 \\
\hline Fatima's new SP & 0.52 & 0.48 & 0.21 & 0.79 & 0.75 & 0.25 & 0.65 & 0.35 \\
\hline
\end{tabular}

TABLE XII. ALI's UPDATED LEARNING STYLE PROFILE

\begin{tabular}{|l|c|c|c|c|c|c|c|c|}
\cline { 2 - 9 } \multicolumn{1}{c|}{} & act & ref & vis & ver & seq & glo & sen & int \\
\hline Ali's SP & 0.5 & 0.5 & 0.6 & 0.4 & 0.8 & 0.2 & 0.7 & 0.3 \\
\hline KSSP_N & 0.37 & 0.63 & 0.75 & 0.25 & 0.67 & 0.33 & 1 & 0 \\
\hline Ali's new SP & 0.44 & 0.56 & 0.68 & 0.32 & 0.73 & 0.27 & 0.85 & 0.15 \\
\hline
\end{tabular}

actual ratings of LOs with the predicted ratings based on questionnaire (initial student profile) $\left(S L_{1 s}\right)$ and the predicted student ratings based on the adapted student profile $\left(L S_{2 s}\right)$. The next section presents experimental results.

\section{EXPERIMENTATION}

In this section, we have conducted a set of experiments to set the parameters and examine our proposed algorithm's effectiveness in terms of updated SP accuracy. The profile adaptation algorithm and student ratings prediction algorithm were implemented in C++ using Visual Studio and Windows Presentation Foundation (WPF) to design the graphical user interface (GUI) as displayed in Fig. 5 and Fig. 6. All the experiments are run on a Windows-based PC with an Intel core i5 processor that has a speed of $2.40 \mathrm{GHz}$ and 16GB of RAM.

\section{A. Dataset description}

To measure the effectiveness of our proposed algorithm, we conducted an experiment in the school of business at the Arab Academy for Science and Technology (AAST). The learners' behaviour data were collected from AAST MOODLE log-file. A total of 80 students participated to this study. It should be noted that this dataset is of similar size or larger than those used in related works: [42] used 75-95 students, [16] used 77 students, [47] used 75 students, [48] used 40 students and [18] used 49 students. First, students filled in the ILS questionnaire developed by FSLSM as explained in [33]. Second, we collected students' behaviour patterns during studying course on different leaning objects format as explained in [33]. During the course, the students were asked to rate each learning object using a 5-level Likert scale; with 1 be "not at all useful" and 5 be "very useful" to their learning.

\section{B. Evaluation metrics}

To evaluation the accuracy of the adaptation algorithm, 2 metrics were used to calculate the accuracy of the learning styles detection: the Mean Absolute Error (MAE) and the Root Mean Squared Error (RMSE). Both metrics measure the average magnitude of the errors in a set of predictions, without considering their direction. They range from 0 to $\infty$ and the smaller their value, the greater the accuracy. They are defined by Eq. (9) and Eq. (10), where $r_{i}$ is the actual student rating of the learning object $\mathrm{i}$ and $\tilde{r}_{i}$ is is the predicted student rating for that learning object, $1 \leq i \leq n$.

$$
\begin{aligned}
\text { MAE } & =\frac{1}{n} \sum_{i=1}^{n}\left|r_{i}-\tilde{r}_{i}\right| \\
\text { RMSE } & =\sqrt{\frac{1}{n} \sum_{i=1}^{n}\left(r_{i}-\tilde{r}_{i}\right)^{2}}
\end{aligned}
$$

RMSE is useful to detect large errors in the prediction that may not be observed through MAE.

\section{Experimental result and discussion}

It was found that the proposed adaption algorithm improves the learning style prediction results in all learning styles dimensions compared to ILS questionnaire of a random sample of 80 students during studying 3 topics and each topic includes 3 lessons. Based on these findings, it can be concluded that monitoring learners' behaviour with time spent on different learning objects' format can improve the accuracy of detecting students' learning styles in an e-learning recommendation system. Thus, this adaptation algorithm can help an e-learning recommendation system improve student performance by recommending the most suitable course learning objects to match their learning styles. Experimental results show that the student 


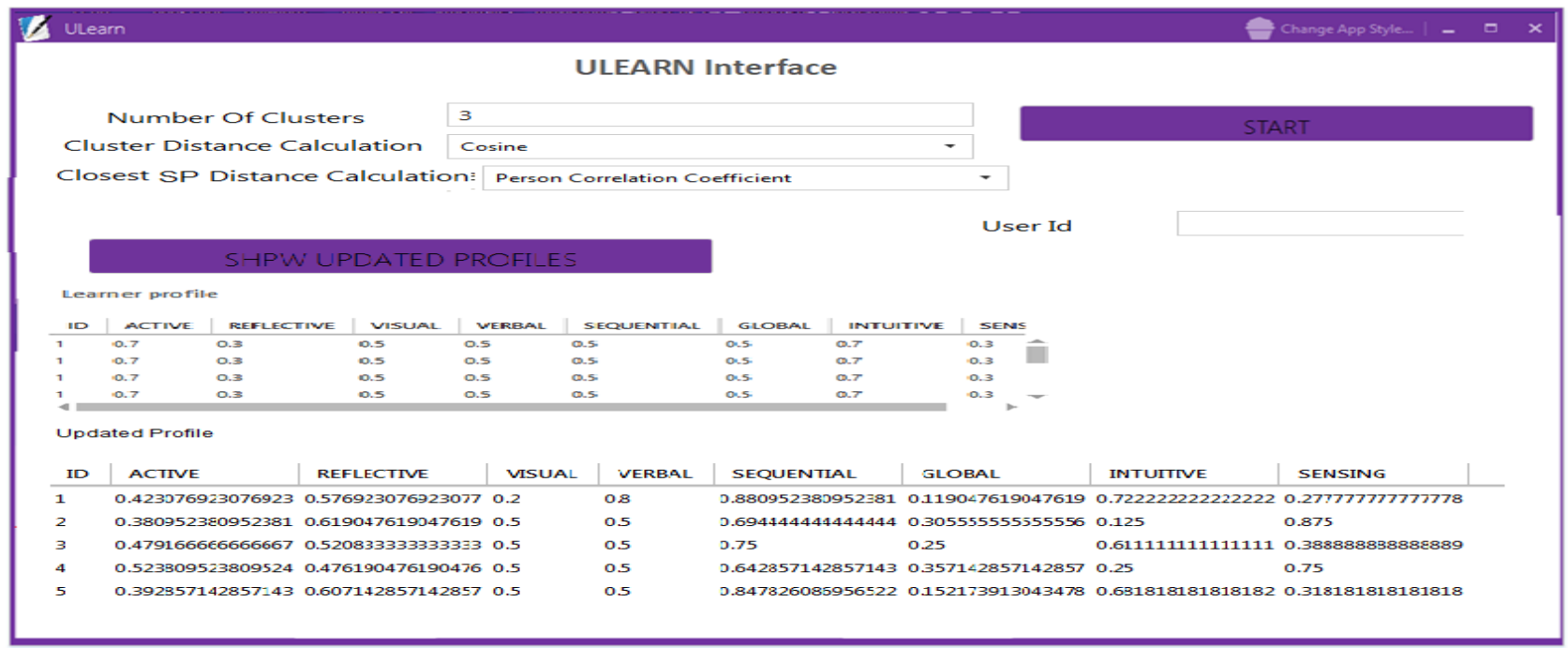

Fig. 5. Dynamic student profile adaptation interface

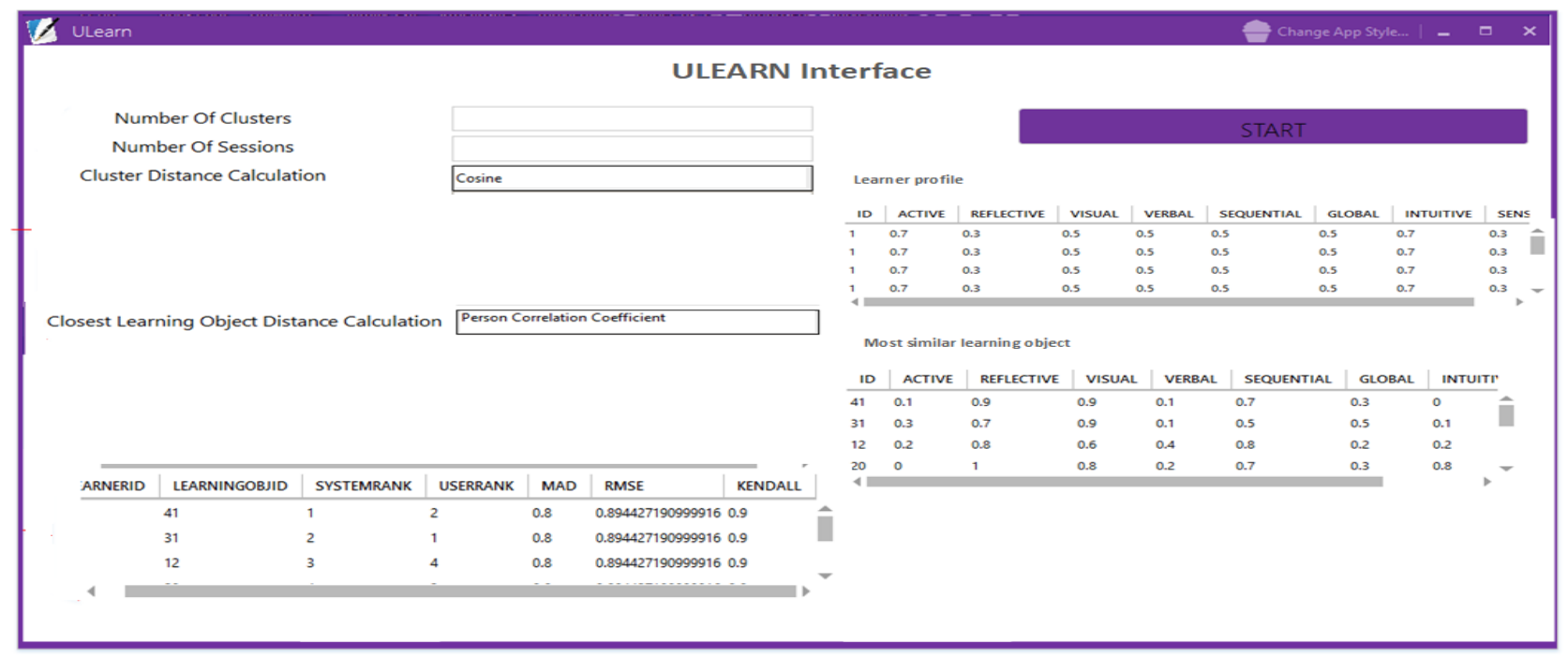

Fig. 6. Student Ratings Prediction interface

rating prediction algorithm has the best accuracy when the student profile is adapted through behaviour $\left(L S_{2} s\right)$ compared to ILS questionnaire $\left(S L_{1} s\right)$ as it can be seen in Fig. 7 and Fig. 8 according to the evaluation metrics MAE and RMSE respectively.

\section{Critical literature OVERView}

This section presents a review of the existing literature relevant to this study with a focus on a brief overview of common techniques used to automatic students learning styles identification based on their learning behaviour patterns as revealed in Table XIII.

\section{CONCLUSIONS AND FUtURE WORK}

Personalised learner profile is increasingly becoming an important area of research in e-learning recommendation systems in which each learner's preferences, interests and contextual information are studied in details. Characteristics

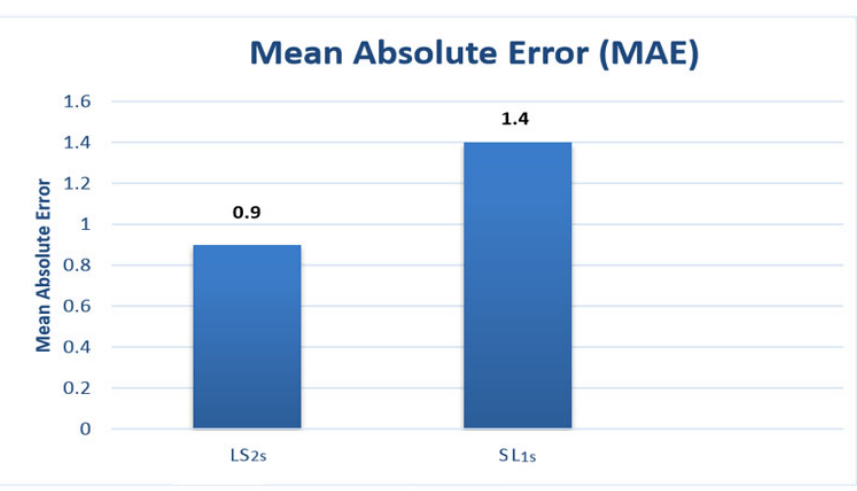

Fig. 7. Accuracy of the adaptation algorithm using MAE

of learning style play vital role in the identification of the learner's learning style preferences. This paper introduced an algorithm for a dynamic student profile based on the Felder- 
TABLE XIII. A COMPARISON BETWEEN EXISTING LEARNING STYLES DETECTION APPROACHES

\begin{tabular}{|c|c|c|c|c|c|c|c|c|c|}
\hline \multirow[b]{2}{*}{ Study } & \multicolumn{9}{|c|}{ Used Algorithms } \\
\hline & $\begin{array}{l}\text { Decision } \\
\text { Tree }\end{array}$ & $\begin{array}{l}\text { Hidden } \\
\text { Markov } \\
\text { Model }\end{array}$ & $\begin{array}{l}\text { Baysian } \\
\text { Network }\end{array}$ & $\begin{array}{l}\text { Rule } \\
\text { based }\end{array}$ & $\begin{array}{l}\text { Support } \\
\text { Vector } \\
\text { Machine }\end{array}$ & $\begin{array}{l}\text { Dynamic } \\
\text { Bayesian } \\
\text { Networks }\end{array}$ & $\begin{array}{l}\text { Naive Bayes } \\
\text { algorithm }\end{array}$ & $\begin{array}{l}\text { neuro-fuzzy } \\
\text { network }\end{array}$ & $\begin{array}{l}\text { Genetic } \\
\text { algorithm }\end{array}$ \\
\hline $\begin{array}{l}\text { [18] learners' preferences are diagnosed } \\
\text { based on their behaviour in order } \\
\text { to customised user interface. }\end{array}$ & $\checkmark$ & $\checkmark$ & & & & & & & \\
\hline $\begin{array}{l}\text { [49] presents an adaptation mechanism to } \\
\text { dynamically adapt learner model. }\end{array}$ & & & $\checkmark$ & & & & & & \\
\hline $\begin{array}{l}\text { [12] presents an automatic student modelling } \\
\text { approach based on students' behaviour patterns. }\end{array}$ & & & & $\checkmark$ & & & & & \\
\hline $\begin{array}{l}\text { [50] this study detect students' learning styles } \\
\text { based on behaviour. }\end{array}$ & & & & & $\checkmark$ & & & & \\
\hline $\begin{array}{l}\text { [51] Presents how it uses Learning Style to } \\
\text { build student model in e-learning environment. }\end{array}$ & & & & & & $\checkmark$ & & & \\
\hline $\begin{array}{l}\text { [52] build student profile according to } \\
\text { learning styles. }\end{array}$ & & & & & & & $\checkmark$ & & \\
\hline $\begin{array}{l}\text { [53] presents intelligent systems for } \\
\text { automatic identification of learning styles } \\
\text { in order to provide an adapted } \\
\text { learning environment. }\end{array}$ & & & & & & & & $\checkmark$ & $\checkmark$ \\
\hline
\end{tabular}

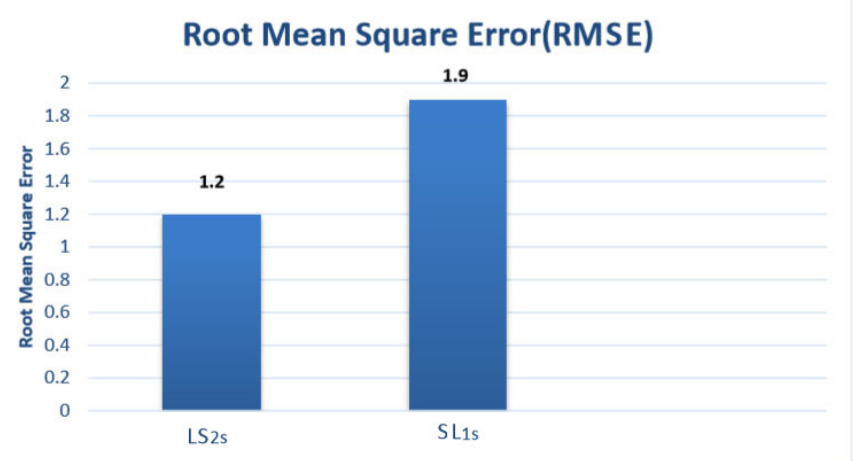

Fig. 8. Accuracy of the adaptation algorithm using RMSE

Silverman learning style model. The algorithm aims at building and frequently updating SPs' learning styles based on students' behaviour in an online course. It relies on three major steps: the first step is based on extracting student learning behaviour patterns that reflect learning styles from MOODLE log file; the second step attempts to calculate student learning styles; finally, the third step is to update students' learning styles dynamically after each topic. Experimental results prove that the proposed algorithm is more accurate than the results obtained using the LS questionnaire. As a future work, we will extend the algorithm to additionally update SPs based on other similar student learning styles and ratings. Furthermore, the collection of patterns is planned to be extended related to additional types of learning objects and activities.

\section{REFERENCES}

[1] C. C. Chen, M. C. Chen, and Y. Sun, "Pva: A self-adaptive personal view agent," Journal of Intelligent Information Systems, vol. 18, no. 2-3, pp. 173-194, 2002.

[2] V. Challam, S. Gauch, and A. Chandramouli, "Contextual search using ontology-based user profiles," in Large Scale Semantic Access to Content (Text, Image, Video, and Sound). LE CENTRE DE HAUTES ETUDES INTERNATIONALES D'INFORMATIQUE DOCUMENTAIRE, 2007, pp. 612-617.

[3] J. Montaner, J. Alvarez-Sabín, C. Molina, A. Anglés, S. Abilleira, J. Arenillas, M. A. González, and J. Monasterio, "Matrix metalloproteinase expression after human cardioembolic stroke: temporal profile and relation to neurological impairment," Stroke, vol. 32, no. 8, pp. 1759-1766, 2001.

[4] J. W. Keefe, Learning Style Theory and Practice. ERIC, 1987.

[5] N. Bajraktarevic, W. Hall, and P. Fullick, "Incorporating learning styles in hypermedia environment: Empirical evaluation," in Proceedings of the workshop on adaptive hypermedia and adaptive web-based systems, no. 1999, 2003, pp. 41-52.

[6] R. M. Felder, L. K. Silverman et al., "Learning and teaching styles in engineering education," Engineering education, vol. 78, no. 7, pp. 674-681, 1988.

[7] S. Graf, C. H. Lan, T.-C. Liu et al., "Investigations about the effects and effectiveness of adaptivity for students with different learning styles," in Advanced Learning Technologies, 2009. ICALT 2009. Ninth IEEE International Conference on. IEEE, 2009, pp. 415-419.

[8] E. Alfonseca, R. M. Carro, E. Martín, A. Ortigosa, and P. Paredes, "The impact of learning styles on student grouping for collaborative learning: a case study," User Modeling and User-Adapted Interaction, vol. 16, no. 3-4, pp. 377-401, 2006.

[9] S. Graf, T.-C. Liu, and K. Kinshuk, "Interactions between students learning styles, achievement and behaviour in mismatched courses," in Proceedings of the international conference on cognition and exploratory learning in digital age (CELDA 2008). IADIS International Conference. Citeseer, 2008, pp. 223-230.

[10] W. A. Taylor, "Computer-mediated knowledge sharing and individual user differences: an exploratory study," European journal of information systems, vol. 13, no. 1, pp. 52-64, 2004.

[11] S. Graf et al., "Using cognitive traits for improving the detection of learning styles," in Database and Expert Systems Applications (DEXA), 2010 Workshop on. IEEE, 2010, pp. 74-78.

[12] S. Graf and S. Viola, "Automatic student modelling for detecting learning style preferences in learning management systems," in Proc. international conference on cognition and exploratory learning in digital age, 2009, pp. 172-179.

[13] N. Ahmad, Z. Tasir, J. Kasim, and H. Sahat, "Automatic detection of learning styles in learning management systems by using literaturebased method," Procedia-Social and Behavioral Sciences, vol. 103, pp. 181-189, 2013.

[14] P. Q. Dung and A. M. Florea, "A literature-based method to automatically detect learning styles in learning management systems," in Proceedings of the 2nd International Conference on Web Intelligence, Mining and Semantics. ACM, 2012, p. 46.

[15] S. Graf, T.-C. Liu et al., "Identifying learning styles in learning management systems by using indications from students' behaviour," in Advanced Learning Technologies, 2008. ICALT'08. Eighth IEEE International Conference. IEEE, 2008, pp. 482-486.

[16] P. García, A. Amandi, S. Schiaffino, and M. Campo, "Evaluating bayesian networks precision for detecting students learning styles," Computers \& Education, vol. 49, no. 3, pp. 794-808, 2007. 
[17] N. Atman, M. M. Inceoğlu, and B. G. Aslan, "Learning styles diagnosis based on learner behaviors in web based learning," in International Conference on Computational Science and Its Applications. Springer, 2009, pp. 900-909.

[18] H. J. Cha, Y. S. Kim, S. H. Park, T. B. Yoon, Y. M. Jung, and J.-H. Lee, "Learning styles diagnosis based on user interface behaviors for the customization of learning interfaces in an intelligent tutoring system," in International Conference on Intelligent Tutoring Systems. Springer, 2006, pp. 513-524.

[19] Ö. Şimşek, N. Atman, M. M. İnceoğlu, and Y. D. Arikan, "Diagnosis of learning styles based on active/reflective dimension of felder and silvermans learning style model in a learning management system," in International Conference on Computational Science and Its Applications. Springer, 2010, pp. 544-555.

[20] C. A. Carver, R. A. Howard, and W. D. Lane, "Enhancing student learning through hypermedia courseware and incorporation of student learning styles," IEEE transactions on Education, vol. 42, no. 1, pp. 33-38, 1999.

[21] S. Schiaffino, P. Garcia, and A. Amandi, "eteacher: Providing personalized assistance to e-learning students," Computers and Education, vol. 51, no. 4, pp. 1744-1754, 2008.

[22] E. Popescu, "Diagnosing students' learning style in an educational hypermedia system," in Cognitive and emotional processes in Webbased education: Integrating human factors and personalization. IGI Global, 2009, pp. 187-208.

[23] Y. Akbulut and C. S. Cardak, "Adaptive educational hypermedia accommodating learning styles: A content analysis of publications from 2000 to 2011," Computers and Education, vol. 58, no. 2, pp. 835-842, 2012.

[24] M. S. Zywno, "A contribution of validation of score meaning for feldersoloman's," in Index of Learning Styles, Proc. 2003 Annual ASEE Conference, ASEE. Citeseer, 2003.

[25] R. M. Felder and J. Spurlin, "Applications, reliability and validity of the index of learning styles," International journal of engineering education, vol. 21, no. 1, pp. 103-112, 2005.

[26] B. L. Brown, "Learning styles and vocational education practice. practice application brief." 1998.

[27] D. Kolb, "Experiential learning as the science of learning and development," 1984.

[28] P. Honey and A. Mumford, "The manual of learning styles (maidenhead, mcgraw-hill)," 1982.

[29] R. Dunn and K. Dunn, "Learning style as a criterion for placement in alternative programs," The Phi Delta Kappan, vol. 56, no. 4, pp. 275-278, 1974.

[30] I. B. Myers, "The myers-briggs type indicator: Manual," 1962.

[31] T.-C. Liu, S. Graf et al., "Coping with mismatched courses: students behaviour and performance in courses mismatched to their learning styles," Educational Technology Research and Development, vol. 57, no. 6, p. 739, 2009.

[32] M. R. Felder and B. A Soloman, "Index of learning styles questionnaire," in https://www.webtools.ncsu.edu/learningstyles/ (accessed 05 October 2018), 1999.

[33] S. Nafea, F. Siewe, and Y. He, "Ulearn: Personalised learners profile based on dynamic learning style questionnaire," in Proceedings of Intelligent Systems(IntelliSys). IEEE, 2018, pp. 1257-1264.

[34] C.-I. Peña, J.-L. Marzo, and J.-L. de la Rosa, "Intelligent agents in a teaching and learning environment on the web," in Proceedings of the international conference on advanced learning technologies. IEEE Learning Technology Task Force. Palmerston North, NZ, 2002, pp. $21-$ 27.

[35] E. Popescu, C. Badica, and L. Moraret, "Accommodating learning styles in an adaptive educational system," Informatica, vol. 34, no. 4, 2010.

[36] P. Paredes and P. Rodriguez, "A mixed approach to modelling learning styles in adaptive educational hypermedia," Advanced Technology for Learning, vol. 1, no. 4, pp. 210-215, 2004.

[37] S. Baldiris, R. Fabregat, C. Mejía, and S. Gómez, "Adaptation decisions and profiles exchange among open learning management systems based on agent negotiations and machine learning techniques," in International Conference on Human-Computer Interaction. Springer, 2009, pp. 12 20.
[38] C. Wolf, "iweaver: towards learning style-based e-learning in computer science education," in Proceedings of the fifth Australasian conference on Computing education, vol. 20. Australian Computer Society, Inc., 2003, pp. 273-279.

[39] H. Imran, M. Belghis-Zadeh, T.-W. Chang, S. Graf et al., "Plors: a personalized learning object recommender system," Vietnam Journal of Computer Science, vol. 3, no. 1, pp. 3-13, 2016.

[40] S. Graf, "Adaptivity in learning management systems focussing on learning styles," 2007.

[41] A. Klašnja-Milićević, B. Vesin, M. Ivanović, and Z. Budimac, "Elearning personalization based on hybrid recommendation strategy and learning style identification," Computers \& Education, vol. 56, no. 3, pp. 885-899, 2011.

[42] A. Latham, K. Crockett, D. McLean, and B. Edmonds, "A conversational intelligent tutoring system to automatically predict learning styles," Computers and Education, vol. 59, no. 1, pp. 95-109, 2012.

[43] G. Araniti, P. De Meo, A. Iera, and D. Ursino, "Adaptively controlling the qos of multimedia wireless applications through" user profiling" techniques," IEEE Journal on Selected Areas in Communications, vol. 21, no. 10, pp. 1546-1556, 2003.

[44] J. E. Thompson, "Student modeling in an intelligent tutoring system," AIR FORCE INST OF TECH WRIGHT-PATTERSON AFB OH, Tech. Rep., 1996.

[45] S. Graf, C. Ives et al., "A flexible mechanism for providing adaptivity based on learning styles in learning management systems," in Advanced Learning Technologies (ICALT), 2010 IEEE 10th International Conference on. IEEE, 2010, pp. 30-34.

[46] S. Nafea, F. Siewe, and Y. He, "A novel algorithm for course learning object recommendation based on student learning styles," 2019.

[47] J. Bernard, T.-W. Chang, E. Popescu, and S. Graf, "Learning style identifier: Improving the precision of learning style identification through computational intelligence algorithms," Expert Systems with Applications, vol. 75, pp. 94-108, 2017.

[48] E. Özpolat and G. B. Akar, "Automatic detection of learning styles for an e-learning system," Computers and Education, vol. 53, no. 2, pp. 355-367, 2009.

[49] S. Alkhuraiji, B. Cheetham, and O. Bamasak, "Dynamic adaptive mechanism in learning management system based on learning styles," in Advanced Learning Technologies (ICALT), 2011 11th IEEE International Conference on. IEEE, 2011, pp. 215-217.

[50] E. S. Amir, M. Sumadyo, D. I. Sensuse, Y. G. Sucahyo, and H. B. Santoso, "Automatic detection of learning styles in learning management system by using literature-based method and support vector machine." IEEE Press, 2016, pp. (41-144).

[51] D. Kelly and B. Tangney, "'first aid for you': getting to know your learning style using machine learning," in Advanced Learning Technologies, 2005. ICALT 2005. Fifth IEEE International Conference on. IEEE, 2005, pp. 1-3.

[52] C. Carmona, G. Castillo, and E. Millán, "Designing a dynamic bayesian network for modeling students' learning styles," in 2008 Eighth IEEE International Conference on Advanced Learning Technologies. IEEE, 2008, pp. 346-350.

[53] R. Zatarain, L. Barrón-Estrada, C. A. Reyes-García, and O. F. ReyesGalaviz, "Applying intelligent systems for modeling students learning styles used for mobile and web-based systems," in Soft Computing for Intelligent Control and Mobile Robotics. Springer, 2010, pp. 3-22. 